\title{
Recent advances in defining and benchmarking complications after esophagectomy
}

\author{
Lucas Goense, Jelle P. Ruurda, Richard van Hillergersberg \\ Department of Surgery, University Medical Center Utrecht, Utrecht, The Netherlands \\ Correspondence to: Lucas Goense, MD, PhD. Department of Surgery, University Medical Center Utrecht, Heidelberglaan 100, 3584CX Utrecht, The \\ Netherlands. Email: L.Goense-2@umcutrecht.nl. \\ Provenance: This is an invited article commissioned by the Academic Editor Dr. Shuangjiang Li (Department of Thoracic Surgery and West China \\ Medical Center, West China Hospital, Sichuan University, Chengdu, China). \\ Comment on: Low DE, Kuppusamy MK, Alderson D, et al. Benchmarking Complications Associated with Esophagectomy. Ann Surg 2019;269:291-8.
}

Submitted Sep 01, 2019. Accepted for publication Sep 26, 2019.

doi: $10.21037 /$ jtd.2019.10.12

View this article at: http://dx.doi.org/10.21037/jtd.2019.10.12

Esophageal surgery is associated with a relatively high surgical postoperative morbidity rate and accounts for a high share of reoperations compared to other surgical procedures (1). In order to improve quality of care there is an increasing demand for transparency of information that aids in comparing these morbidity-related outcomes across institutions, national audits and trials $(2,3)$. This information can be used to provide feedback to individual centers and assist them with developing targeted quality improvement initiatives that might lead to improved quality of care and better overall outcomes $(2,3)$. However, relevant comparison of outcomes between centers requires consistency in data collection. The lack of standardized definitions for reporting complications so far has hindered fair outcome assessment after esophagectomy (4). It has also resulted in a long debate within the surgical community on which prevalence of complications can be reasonably expected after esophagectomy.

For this reason, the Esophageal Complications Consensus Group (ECCG) was formed in 2011 with the aim to produce a reproducible system for reporting outcomes associated with esophagectomy (5). Through a series of Delphi surveys among 21 renowned high-volume esophageal centers representing 14 countries the ECCG has developed standardized definitions for reporting complications after esophagectomy (5). This has enabled a tool for consistent reporting and formulating goals for quality improvement projects. As a result, the ECCG definitions have, at the time of writing, been used in over 250 papers and have been successfully implemented in national audits such as the Dutch Upper Gastrointestinal Cancer Audit (DUCA) (6).

Having produced a system for reporting outcomes associated with esophagectomy, the centers involved in the ECCG prospectively recorded data of all resections according to the ECCG definitions over a 2-year period (7). With this data they have provided a benchmark of morbidity and mortality associated with esophageal resection. Some 2,704 esophageal resection were included and involved $47.9 \%$ minimally invasive resections and $52.1 \%$ open procedures. The overall prevalence of complications was $59 \%$, and the most common complications were pneumonia (14.6\%), atrial dysrhythmia (14.5\%) and anastomotic leakage $(11.4 \%)$. Average 30 - and 90 -day mortality was $2.4 \%$ and $4.5 \%$, respectively (7).

The authors are to be commended on this fundamental, and in many ways essential contribution, as it represents current international practice in a field where studies have been limited by a lack of standardized definitions. Yet, future studies are needed to modify and optimize the definitions and 'benchmarks' currently proposed by the ECCG. The benchmarks for complications provided by the ECCG are presented as percentage averages of all the patients included in the database and does not differentiate between surgical approach (transhiatal or transthoracic), surgical technique (full minimally invasive, open or hybrid), differences in co- 


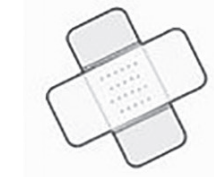

Any complication $\leq 55.7 \%$

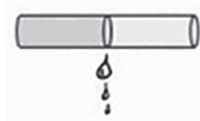

Anastomotic leakages $\leq 20.0 \%$

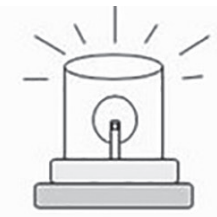

Severe complications $\leq 30.8 \%$

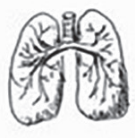

Pulmonary complications $\leq 31.6 \%$

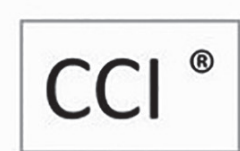

Overall morbidity $\leq 40.8$

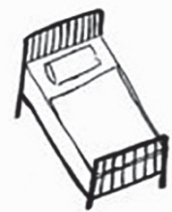

Readmission rate $\leq 18.0 \%$

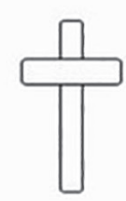

Mortality rate $\leq 1.0 \%$

Figure 1 Benchmark values of minimally invasive esophagectomy. Results better than the given thresholds are considered to be within the benchmark. [Reprinted with permission from (12)].

morbidity status, and center-related differences. These differences influence the occurrence of complications and therewith hamper fair comparisons between centers and will leave room for debate on the prevalence of outcomes that can be reasonably expected per approach and technique $(8,9)$. For instance, the rates of overall complications, pneumonia and anastomotic leakage are higher in DUCA compared to the benchmark set by the centers participating in the ECCG (6). These differences were, by the authors of that same paper, largely explained by differences in patient and treatment related characteristics.

To overcome these differences future studies could use the ECCG definitions to provide benchmark values for specific surgical techniques and groups of patients (i.e., risk stratification). The concept of benchmarking is to provide a realistic reference point of the best possible outcome-not just the average-for a specific surgical approach and for patients with the lowest risk of postoperative complications ('Ideal' patients) (10). For this reason, in benchmarking it is recommended to set the benchmark cut-off at the 75th percentile of the median proportion of each included center to indicate acceptable outcome quality (10). Another recently published paper has used this technique-while using the complication definitions of the ECCG-to provide benchmarks for minimally invasive transthoracic esophageal resections based on 1,057 patients (11). Only low risk patients (ASA score $<2$, age $<65$, BMI 19-29) were included and the benchmark was set at the 75 th percentile of the median outcome parameters of the 13 high-volume centers. The benchmarks provided by this study are presented in Figure 1, and should be interpreted as the upper limits of the 'best possible' outcome (12). As such, results from other centers or studies that are within these benchmark thresholds (the 75th percentile of the medians) will indicate acceptable outcome quality.

Further identification and refinement of benchmarks should be developed as there are potential risks associated with providing only one general complication benchmark for all esophageal cancer patients. For example, it could lead to institutions undertaking only low-risk procedures (e.g., minimal comorbidity/frailty) to lower their complication rates. This could become problematic in patients with esophageal cancer because curative treatment often still requires highly complex surgery, which accordingly is associated with an increased risk of perioperative complications, but also with improved overall survival (13). Having a high complication rate does not necessarily exclude providing good overall survival outcomes. As these two issues are inseparable, it should be recommended to include survival analyses and different risk-profiles in the benchmark (14).

Future studies are also likely to lead to modifications of the definitions of complications set by the ECCG. For example, pneumonia has been defined according to the clinical pulmonary infection score (CPIS) (15). However, the CPIS has been developed in patients with ventilatorassociated pneumonia, without validation in patients with postoperative pneumonia. Furthermore, it has been demonstrated that the CPIS cannot directly be translated to other populations, as validation in trauma patients 
failed (16). Considering these limitations and to fill in this gap a specific scoring model to define pneumonia after esophagectomy has been created; the Uniform Pneumonia Score (UPS) $(17,18)$. Inclusion of the internally and externally validated UPS in the ECCG definitions will likely improve outcome reporting and comparison of this complication after esophagectomy (17).

In summary, reporting outcomes using standardized definitions in esophageal surgery is an essential step to allow accurate comparison of outcomes across institutions, national audits and trials. Reliable comparisons could help to reveal significant differences in outcomes and therewith aid in the development of targeted quality improvement initiatives. Subsequently it can be used to assess the impact of such initiatives. Therefore, a more widespread adoption and refinement of the ECCG platform is recommended to facilitate communication and evaluation of different approaches for the improvement of outcomes after esophagectomy.

\section{Acknowledgments}

None.

\section{Footnote}

Conflicts of Interest: The authors have no conflicts of interest to declare.

Ethical Statement: The authors are accountable for all aspects of the work in ensuring that questions related to the accuracy or integrity of any part of the work are appropriately investigated and resolved.

\section{References}

1. Busweiler LA, Wijnhoven BP, van Berge Henegouwen MI, et al. Early outcomes from the Dutch Upper Gastrointestinal Cancer Audit. Br J Surg 2016;103:1855-63.

2. Ellis RJ, Ko CY. Improving the quality of surgical care: The American College of Surgeons National Surgical Quality Improvement Program. Rev Calid Asist 2017;32:301-2.

3. Ko CY, Hall BL, Hart AJ, et al. The American College of Surgeons National Surgical Quality Improvement Program: achieving better and safer surgery. Jt Comm J Qual patient Saf 2015;41:199-204.
4. Blencowe NS, Strong S, McNair AG, et al. Reporting of Short-Term Clinical Outcomes After Esophagectomy. Ann Surg 2012;255:658-66.

5. Low DE, Alderson D, Cecconello I, et al. International consensus on standardization of data collection for complications associated with esophagectomy: Esophagectomy Complications Consensus Group (ECCG). Ann Surg 2015;262:286-94.

6. van der Werf LR, Busweiler LA, van Sandick JW, et al. Reporting National Outcomes After Esophagectomy and Gastrectomy According to the Esophageal Complications Consensus Group (ECCG). Ann Surg 2019. [Epub ahead of print].

7. Low DE, Kuppusamy MK, Alderson D, et al. Benchmarking Complications Associated with Esophagectomy. Ann Surg 2019;269:291-8.

8. Biere SS, van Berge Henegouwen MI, Maas KW, et al. Minimally invasive versus open oesophagectomy for patients with oesophageal cancer: a multicentre, open-label, randomised controlled trial. Lancet 2012;379:1887-92.

9. Papenfuss WA, Kukar M, Attwood K, et al. Transhiatal versus transthoracic esophagectomy for esophageal cancer: A 2005-2011 NSQIP comparison of modern multicenter results. J Surg Oncol 2014;110:298-301.

10. Staiger RD, Schwandt H, Puhan MA, et al. Improving surgical outcomes through benchmarking. Br J Surg 2019;106:59-64.

11. Schmidt HM, Gisbertz SS, Moons J, et al. Defining Benchmarks for Transthoracic Esophagectomy. Ann Surg 2017;266:814-21.

12. Staiger RD, Gutschow CA. Benchmark analyses in minimally invasive esophagectomy-impact on surgical quality improvement. J Thorac Dis 2019;11:S771-6.

13. Lagergren J, Smyth E, Cunningham D, et al. Oesophageal cancer. Lancet 2017;390:2383-96.

14. Butler J, Foot C, Bomb M, et al. The International Cancer Benchmarking Partnership: An international collaboration to inform cancer policy in Australia, Canada, Denmark, Norway, Sweden and the United Kingdom. Health Policy 2013;112:148-55.

15. Guidelines for the management of adults with hospitalacquired, ventilator-associated, and healthcare-associated pneumonia. Am J Respir Crit Care Med 2005;171:388-416.

16. Croce MA, Swanson JM, Magnotti LJ, et al. The futility of the Clinical Pulmonary Infection Score in trauma patients. J Trauma 2006;60:523-7; discussion 527-8. 
17. Seesing MF, Wirsching A, Van Rossum PS, et al. Defining pneumonia after esophagectomy for cancer: Validation of the Uniform Pneumonia Score in a high volume center in North America. Dis Esophagus 2018.

Cite this article as: Goense L, Ruurda JP, van Hillergersberg R. Recent advances in defining and benchmarking complications after esophagectomy. J Thorac Dis 2019;11(11):E243-E246. doi: 10.21037/jtd.2019.10.12 doi: 10.1093/dote/doy002.

18. van der Sluis PC, Verhage RJ, van der Horst S, et al. A new clinical scoring system to define pneumonia following esophagectomy for cancer. Dig Surg 2014;31:108-16. 